\title{
Moderate altitude is not associated with adverse postoperative outcomes for patients undergoing bidirectional cavopulmonary anastomosis and Fontan operation: A comparative study among Denver, Edmonton, and Toronto
}

\author{
Zhi Zhou, BEng, ${ }^{\text {a }}$ Sunil P. Malhotra, MD,${ }^{\mathrm{b}}$ Xiaoyang Yu, MD, ${ }^{\mathrm{c}}$ Jennifer Rutledge, MD, ${ }^{\mathrm{d}}$ \\ Ivan M. Rebeyka, MD, ${ }^{\mathrm{e}}$ David B. Ross, MD, ${ }^{\mathrm{e}}$ Christopher Rausch, MD, ${ }^{\mathrm{g}}$ Hong Gu, MD, PhD, ${ }^{\mathrm{f}}$ \\ Brian McCrindle, MD, ${ }^{a}$ Francois Lacour-Gayet, MD, ${ }^{\mathrm{b}}$ Dunbar Ivy, MD, ${ }^{\mathrm{g}}$ and Jia Li, MD, PhD ${ }^{\mathrm{c}, \mathrm{d}}$
}

\begin{abstract}
Objective: Outcomes of patients with single ventricle physiology undergoing cavopulmonary palliations depend on pulmonary vascular resistance (PVR) and have been suggested to be adversely affected by living at elevated altitude. We compared the pulmonary hemodynamic data in correlation with postoperative outcomes at the 3 centers of Denver, Edmonton, and Toronto at altitudes of 1604, 668, and 103 meters, respectively.
\end{abstract}

\begin{abstract}
Methods: Hemodynamic data at pre-bidirectional cavopulmonary anastomosis (BCPA) and pre-Fontan catheterization between 1995 and 2007 were collected. Death from cardiac failure or heart transplantation in the same period was used to define palliation failure.
\end{abstract}

\begin{abstract}
Results: There was no significant correlation between altitude (ranged from 1 to 2572 meters) and PVR, pulmonary artery pressure (PAP) or transpulmonary gradient (TPG) at pre-BCPA and pre-Fontan catheterization. BCPA failure occurred in $11(9.2 \%)$ patients in Denver, $3(2.9 \%)$ in Edmonton, and $34(11.9 \%)$ in Toronto. Fontan failure occurred in $3(6.1 \%)$ patients in Denver, $5(7.2 \%)$ in Edmonton, and $11(7.0 \%)$ in Toronto. There was no significant difference in BCPA and Fontan failure among the 3 centers. BCPA failure positively correlated with PVR and the presence of a right ventricle as the systemic ventricle. Fontan failure positively correlated with PAP and TPG.

Conclusions: Moderate altitude is not associated with an increased PVR or adverse outcomes in patients with a functional single ventricle undergoing BCPA and the Fontan operation. The risk factors for palliation failure are higher PVR, PAP, and TPG and a systemic right ventricle, but not altitude. Our study reemphasizes the importance of cardiac catheterization assessments of pulmonary hemodynamics before BCPA and Fontan operations. (J Thorac Cardiovasc Surg 2013;146:1165-71)
\end{abstract}

The surgical management of a functional single ventricle has evolved into a staged pathway, which includes bidirectional cavopulmonary anastomosis (BCPA) and Fontan operations, to route the systemic venous return into the pulmonary circulation. Therefore, low pulmonary arterial pressure (PAP) and vascular resistance (PVR) are major criteria for optimal outcomes after the cavopulmonary palliations. ${ }^{1,2}$

Atmospheric pressure and partial pressure of oxygen are inversely proportional to altitude. Altitude-related hypoxia

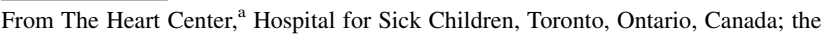
Division of Cardiac Surgery, ${ }^{\mathrm{b}}$ Children's Hospital, Denver, Colo; the Department of Pediatrics, ${ }^{\mathrm{c}}$ University of Alberta, Edmonton, Alberta, Canada; the Division of Pediatric Cardiology, ${ }^{\mathrm{d}}$ Stollery Children's Hospital, Edmonton, Alberta, Canada; the Division of Surgery, ${ }^{\mathrm{e}}$ Stollery Children's Hospital, Edmonton, Alberta, Canada; the Division of Pediatric Cardiology, ${ }^{\mathrm{f}}$ An Zhen Hospital, Beijing, China; and the Division of Cardiology, ${ }^{\mathrm{g}}$ Children's Hospital, Denver, Colo.

Disclosures: Authors have nothing to disclose with regard to commercial support.

Received for publication May 7, 2012; revisions received Nov 25, 2012; accepted for publication Dec 18, 2012; available ahead of print Jan 25, 2013.

Address for reprints: Jia Li, MD, PhD, Clinical Physiology Research Center, Capital Institute of Pediatrics, 2 Yabao Road, Chaoyang District, Beijing 100020, China (E-mail: j1al1@yahoo.com).

$0022-5223 / \$ 36.00$

Copyright (c) 2013 by The American Association for Thoracic Surgery

http://dx.doi.org/10.1016/j.jtcvs.2012.12.073
}

may cause pulmonary vasoconstriction resulting in an elevated PAP and PVR. ${ }^{3-5}$ Intuitively, altitude has been considered to negatively affect pulmonary hemodynamics and thus postoperative outcomes for patients with functional single ventricle. ${ }^{1,6,7}$ However, reports from the single-center studies at moderate altitude in Denver, Colorado, and Salt Lake City, Utah, have shown favorable outcomes that are comparable with centers at sea level. ${ }^{7,8}$ In Denver's study, risk factors for palliation failure included higher PAP and PVR. ${ }^{8}$ A multicentered study from different attitudes with a direct comparison of hemodynamics and postoperative outcomes in age-matched populations is necessary to demonstrate an impact of altitude. Therefore, we aimed, first, to compare the hemodynamic variables at routine pre-BCPA and pre-Fontan cardiac catheterization and correlate them to the postoperative outcomes among the 3 centers in Denver, Colorado (altitude, 1604 meters), Edmonton, Alberta (668 meters), and Toronto, Ontario (103 meters), which represent an altitude range of most worldwide centers performing staged palliations for patients with functional single ventricle. The second aim was to further examine the effect of pulmonary hemodynamics on the postoperative outcomes in these patients. 


\section{Abbreviations and Acronyms \\ $\mathrm{BCPA}=$ bidirectional cavopulmonary anastomosis \\ PAP = pulmonary arterial pressure \\ PVR = pulmonary vascular resistance \\ $\mathrm{TPG}=$ transpulmonary pressure gradient \\ $\mathrm{VEDP}=$ ventricular end-diastolic pressure}

\section{METHODS \\ Patients}

A retrospective review of patient records was performed in accordance with research protocols approved by the institutional Research Ethics Boards at Children's Hospital in Denver, Colorado, Stollery Children's Hospital in Edmonton, Alberta, Canada, and the Hospital for Sick Children in Toronto, Ontario, Canada. Data were collected in patients with functional single ventricle who underwent a BCPA between January 1995 and March 2007. Patients with genetic syndromes were excluded. A total of 506 patients born between January 1, 1995, and December 31, 2006, were enrolled in the study, including 119 patients in Denver, 102 in Edmonton, and 285 in Toronto.

\section{Diagnosis and Surgical Techniques}

Table 1 summarizes the specific cardiac diagnoses of patients from the 3 centers, the morphologic characteristics of the functional systemic ventricle, and surgery performed before BCPA. Surgical techniques of BCPA and Fontan operations did not differ among the 3 centers, representing the standard worldwide practice. At BCPA, the superior vena cava was transected at the level of the right pulmonary artery and anastomosed to the superior border of the right pulmonary artery. Extracardiac Fontan operation was performed in the majority of patients using an 18- or 20-mm expanded polytetrafluoroethylene graft anastomosed to the undersurface of the main pulmonary artery, offset to the left of the BCPA. For patients who underwent a fenestration (24 in Denver, 51 in Edmonton, and 110 in Toronto), a 4- to 5-mm fenestration was created between the Fontan conduit and the common atrial free wall.

\section{Altitude and Hemodynamic Assessments}

The altitude and diagnoses were recorded at the patient's place of residence at time of BCPA and displayed in Figure 1.

Hemodynamic data were collected at routine pre-BCPA and pre-Fontan cardiac catheterizations, including systolic and mean PAP, mean left atrial or pulmonary capillary wedge pressure, transpulmonary pressure gradient (TPG), ventricular end-diastolic pressure (VEDP), arterial oxygen saturation, and pulmonary arterial and venous oxygen saturations. At preBCPA, pulmonary arterial oxygen saturation is equal to the arterial oxygen saturation in patients after the Norwood procedure.

Oxygen consumption was uniformly recalculated for all patients using the Lindahl equation, ${ }^{9}$ as follows:

For children weighing less than $10 \mathrm{~kg}$, oxygen consumption $(\mathrm{mL} /$ $\min )=(6.8 \times$ weight $)+8.0$.

For those weighing more than $10 \mathrm{~kg}$, oxygen consumption $(\mathrm{mL} /$ $\min )=(4.0 \times$ weight $)+35.8$.

Oxygen consumption was indexed to body surface area. Pulmonary blood flow was calculated using the direct Fick principle to allow the derivation of PVR.

\section{Follow-up and Outcomes}

Follow-up protocol was similar among the 3 centers, by which patients were examined at about 6-month intervals and more frequently if the child's status changed. Follow-up information was obtained from the last patient assessment by the pediatric cardiologist or referring pediatrician until March 2007. It was completed in $112(94 \%)$ patients at a median period of 3.0 years (range, 0.02-12.5 years) in Denver; in 93 (91.2\%) patients at a median period of 6.1 years (range, $0.79-12.3$ years) in Edmonton, and in $251(88.1 \%)$ patients at a median period of 3.2 years (range, $0-11.4$ years) in Toronto. In-hospital death was defined as death occurring during the same hospital admission after the BPCA or Fontan operation. Palliation failure after BCPA and Fontan operation was defined as death from cardiac failure or need for heart transplantation.

\section{Data Analysis}

Data were described as median with range or mean with standard deviation. Survival was calculated as the number of patients undergoing BCPA minus the number of deaths divided by the number of patients undergoing BCPA. Palliation failure rate was calculated as the number of deaths and needs for heart transplantations divided by the number of patients undergoing BCPA or Fontan operation for 1, 5, and 10 years after each palliation. The $\chi^{2}$ test was used to examine the difference in the distribution of cardiac diagnoses and surgical procedures before BCPA in the 3 centers. Analysis of variance was used to compare the demographic data (age, weight, and body surface area) in patients among the 3 centers. Simple linear regression was used to examine the correlations between continuous data including altitude, center (Denver as 0, Edmonton as 1, and Toronto as 2, according to the ascending levels of altitude), and hemodynamic variables. Logistic regression was used to determine the relationship between the categorical data of palliation failures, altitude, and hemodynamic variables. Paired $t$ test was used to compare the variables between BCPA and Fontan operation. All data analysis was performed using SAS statistical software version 9.3 (SAS Institute, Inc, Cary, NC).

\section{RESULTS \\ Patients}

The altitude ranged from 1 to 2572 meters in the patients from the 3 centers. There was no significant difference in age, weight, or body surface area at pre-BCPA or preFontan catheterization among the centers (Table 2). There were 104,80 , and 259 patients undergoing pre-BCPA catheterization; 119, 102, and 285 patients undergoing BCPA surgery; and 1, 0, and 14 in-hospital deaths in Denver, Edmonton, and Toronto, respectively. Subsequently, there were 49,59 , and 170 patients undergoing pre-Fontan catheterization; 49, 69, and 155 patients undergoing the Fontan operation; and 0,1 , and 3 in-hospital deaths for early postoperative mortality in Denver, Edmonton, and Toronto, respectively. In Denver, there was 1 patient who did not have pre-BCPA catheterization among the 11 patients with BCPA failure. In Edmonton, there was 1 patient who did not have pre-BCPA catheterization among the 3 patients with BCPA failure, and 1 patient with no pre-Fontan catheterization among the 5 patients with Fontan failure. In Toronto, there were 2 patients who did not have preBCPA catheterization among the 31 patients with BCPA failure. On the other hand, among the 17 patients who had pre-Fontan catheterization but did not have the Fontan operation, 4 patients have had PVR above 3 Wood units $\times \mathrm{m}^{2}\left(3.4,4.5,7.3\right.$, and 8.7 Wood units $\times \mathrm{m}^{2}$, respectively), 2 patients (PVR, 7.3 and 8.7 Wood units $\times \mathrm{m}^{2}$, respectively) lost to follow-up, and the other 2 patients did not have BCPA failure. In Edmonton, 6 patients had pre-Fontan 
TABLE 1. The distribution of cardiac diagnoses and surgical procedures before BCPA in the 3 centers

\begin{tabular}{lcccc}
\hline & $\begin{array}{c}\text { Denver, } \\
\mathbf{n}(\%)\end{array}$ & $\begin{array}{c}\text { Edmonton, } \\
\mathbf{n}(\%)\end{array}$ & $\begin{array}{c}\text { Toronto, } \\
\mathbf{n}(\%)\end{array}$ & $\begin{array}{c}\boldsymbol{P} \\
\text { value }\end{array}$ \\
\hline No. of patients & 119 & 102 & 285 & \\
Diagnosis & & & & \\
$\quad$ HLHS & $26(21.8)$ & $42(41.1)$ & $101(35.4)$ & .005 \\
TA & $35(29.4)$ & $19(18.6)$ & $45(15.8)$ & .01 \\
PA+VSD & $9(7.6)$ & $9(8.8)$ & $15(5.3)$ & .42 \\
PA+IVS, hypoplastic RV & $11(9.2)$ & $6(5.9)$ & $25(8.8)$ & .59 \\
DILV, L-TGA, PS & $11(9.2)$ & $16(15.7)$ & $23(8.1)$ & .02 \\
DORV & $12(10.0)$ & $4(3.9)$ & $33(11.6)$ & .07 \\
Complex TGA & $6(5.0)$ & $4(3.9)$ & $20(7.0)$ & .19 \\
Ebstein & $3(2.5)$ & $1(0.98)$ & $9(3.2)$ & .62 \\
Unbalanced AVSD & $6(5.0)$ & $1(0.98)$ & $14(4.9)$ & .19 \\
Functional single ventricle & \multicolumn{5}{c}{} & \\
RV & $36(30)$ & $50(49)$ & $157(55)$ & $<.0001$ \\
LV & $83(70)$ & $52(51)$ & $128(45)$ & $<.0001$ \\
Palliative procedures performed before BCPA & & \\
Isolated MBTS & $40(33.6)$ & $33(32.3)$ & $103(36.1)$ & .02 \\
Norwood & $30(25.2)$ & $50(49.2)$ & $118(41.4)$ & .05 \\
PA band & $16(13.4)$ & $12(11.8)$ & $45(15.8)$ & .99 \\
Unifocalization & $3(2.5)$ & $2(2.0)$ & $8(2.8)$ & .74 \\
Ductal stent & $1(0.8)$ & $2(2.0)$ & $2(0.7)$ & .30 \\
\hline
\end{tabular}

HLHS, Hypoplastic left heart syndrome; $T A$, tricuspid atresia; $P A$, pulmonary atresia; $V S D$, ventricular septal defect; $I V S$, intact ventricular septum; $R V$, right ventricle; $D I L V$, double-inlet left ventricle; $L-T G A$, levo-transposition of the great arteries; $P S$, pulmonary stenosis; $D O R V$, double-outlet right ventricle; TGA, transposition of the great arteries; $A V S D$, atrioventricular septal defect; $L V$, left ventricle; $B C P A$, bidirectional cavopulmonary anastomosis; MBTS, modified Blalock-Taussig shunt.

catheterization but did not have the Fontan operation; PVR was less than 3 Wood units $\times \mathrm{m}^{2}$ in all and none had BCPA failure. In Toronto, among 28 patients who had pre-Fontan catheterization but did not have the Fontan operation, PVR was above 3 Wood units $\times \mathrm{m}^{2}$ in 3 patients $(3.1,4.8$, and 6.5 Wood units $\times \mathrm{m}^{2}$, respectively), the patient with PVR 6.5 Wood units $\times \mathrm{m}^{2}$ died 15 months after BCPA; the other 2 patients did not have BCPA failure.

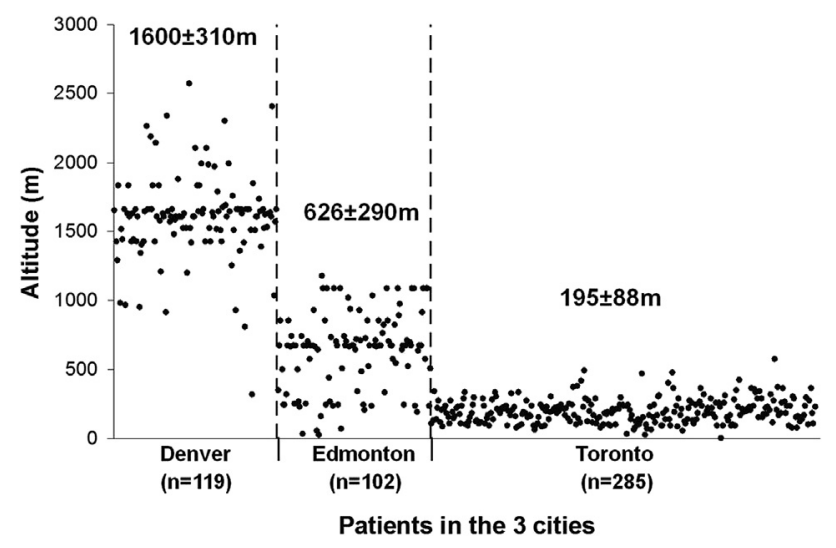

FIGURE 1. The altitude distribution at the patient's place of residence at time of BCPA from the 3 centers.
TABLE 2. Demographic and hemodynamic data at pre-BCPA and pre-Fontan catheterization

\begin{tabular}{|c|c|c|c|}
\hline & $\begin{array}{c}\text { Denver } \\
(\mathrm{n}=119)\end{array}$ & $\begin{array}{c}\text { Edmonton } \\
(\mathbf{n}=102)\end{array}$ & $\begin{array}{c}\text { Toronto } \\
(\mathbf{n}=\mathbf{2 8 5})\end{array}$ \\
\hline \multicolumn{4}{|l|}{ Pre-BCPA catheterization } \\
\hline No. of patients & 104 & 80 & 259 \\
\hline Age $(\mathrm{mo})$ & $7.6 \pm 7.9$ & $6.8 \pm 5.3$ & $6.3 \pm 10.1$ \\
\hline Weight $(\mathrm{kg})$ & $6.8 \pm 1.2$ & $6.0 \pm 1.9$ & $5.8 \pm 2.7$ \\
\hline Body surface area $\left(\mathrm{m}^{2}\right)$ & $0.32 \pm 0.07$ & $0.32 \pm 0.07$ & $0.31 \pm 0.09$ \\
\hline PAP $(\mathrm{mm} \mathrm{Hg})^{*}$ & $15.4 \pm 5.3$ & $14.6 \pm 5.8$ & $15.0 \pm 5.6$ \\
\hline $\mathrm{TPG}(\mathrm{mm} \mathrm{Hg})^{*}$ & $8.1 \pm 4.4$ & $9.8 \pm 5.1$ & $8.9 \pm 5.3$ \\
\hline PVR $\left(\text { Wood units } \times \mathrm{m}^{2}\right)^{*}$ & $2.5 \pm 1.8$ & $3.0 \pm 2.0$ & $2.5 \pm 1.3$ \\
\hline VEDP (mm Hg) & $7.1 \pm 3.1$ & $7.6 \pm 4.5$ & $7.3 \pm 2.9$ \\
\hline $\mathrm{SaO}_{2}(\%)^{*}$ & $75.5 \pm 6.4$ & $79.7 \pm 7.3$ & $78.1 \pm 8.0$ \\
\hline \multicolumn{4}{|l|}{ Pre-Fontan catheterization } \\
\hline No. of patients & 49 & 59 & 170 \\
\hline Age (mo) & $40.2 \pm 21.3$ & $41.3 \pm 5.3$ & $33.7 \pm 12.5$ \\
\hline Weight $(\mathrm{kg})$ & $14.3 \pm 4.9$ & $14.6 \pm 8.7$ & $12.9 \pm 2.5$ \\
\hline Body surface area $\left(\mathrm{m}^{2}\right)$ & $0.61 \pm 0.15$ & $0.61 \pm 0.21$ & $0.60 \pm 0.09$ \\
\hline $\mathrm{PAP}(\mathrm{mm} \mathrm{Hg})^{*}$ & $11.9 \pm 4.1$ & $11.2 \pm 4.5$ & $11.0 \pm 4.5$ \\
\hline $\mathrm{TPG}(\mathrm{mm} \mathrm{Hg})$ & $5.2 \pm 2.1$ & $6.4 \pm 2.9$ & $5.7 \pm 1.7$ \\
\hline PVR (Wood units $\left.\times \mathrm{m}^{2}\right) *$ & $1.9 \pm 1.6$ & $2.5 \pm 1.4$ & $1.9 \pm 1.0$ \\
\hline VEDP (mm Hg) & $8.8 \pm 5.3$ & $6.7 \pm 3.8$ & $7.4 \pm 3.0$ \\
\hline $\mathrm{SaO}_{2}(\%)^{*}$ & $81.5 \pm 5.8$ & $83.6 \pm 5.7$ & $85.6 \pm 8.3$ \\
\hline
\end{tabular}

There was no statistical significance in the correlations between the centers and any of the values. $B C P A$, Bidirectional cavopulmonary anastomosis; $P A P$, pulmonary arterial pressure; $T P G$, transpulmonary gradient; $P V R$, pulmonary vascular resistance; $V E D P$, systemic ventricular end-diastolic pressure; $\mathrm{SaO}_{2}$, arterial oxygen saturation *Indicates $P<.0001$ in the decrease in PAP, TPG, and PVR and the increase in $\mathrm{SaO}_{2}$ from pre-BCPA to pre-Fontan catheterization.

\section{Comparison of Pre-BCPA and Pre-Fontan Hemodynamics and Postoperative Outcomes in the 3 Centers}

Figure 2 shows the postoperative outcomes of the patients in the 3 centers. Hemodynamic data at pre-BCPA and preFontan cardiac catheterization are shown in Table 2. There was no significant relationship between centers and PAP, PVR, TPG, VEDP, or arterial oxygen saturation. As shown in Table 3, there was no significant relationship between centers and cavopulmonary palliation failure after BCPA and the Fontan operation. In addition, the survival at any of the follow-up periods after BCPA did not significantly relate to the centers.

\section{Relationship Between Altitude, Hemodynamics, and Outcome}

When data from the patients with pulmonary hemodynamic data in the 3 centers were analyzed together, there were no significant correlations between altitude and hemodynamic variables at pre-BCPA and pre-Fontan catheterization, nor palliation failure after BCPA or the Fontan operation (Figure 3). BCPA failure correlated positively with PVR $(P=.02)$ and the presence of a systemic right ventricle $(P=.005)$. Fontan failure was correlated positively with PAP $(P=.04)$ and TPG $(P=.06)$ (Table 4). 


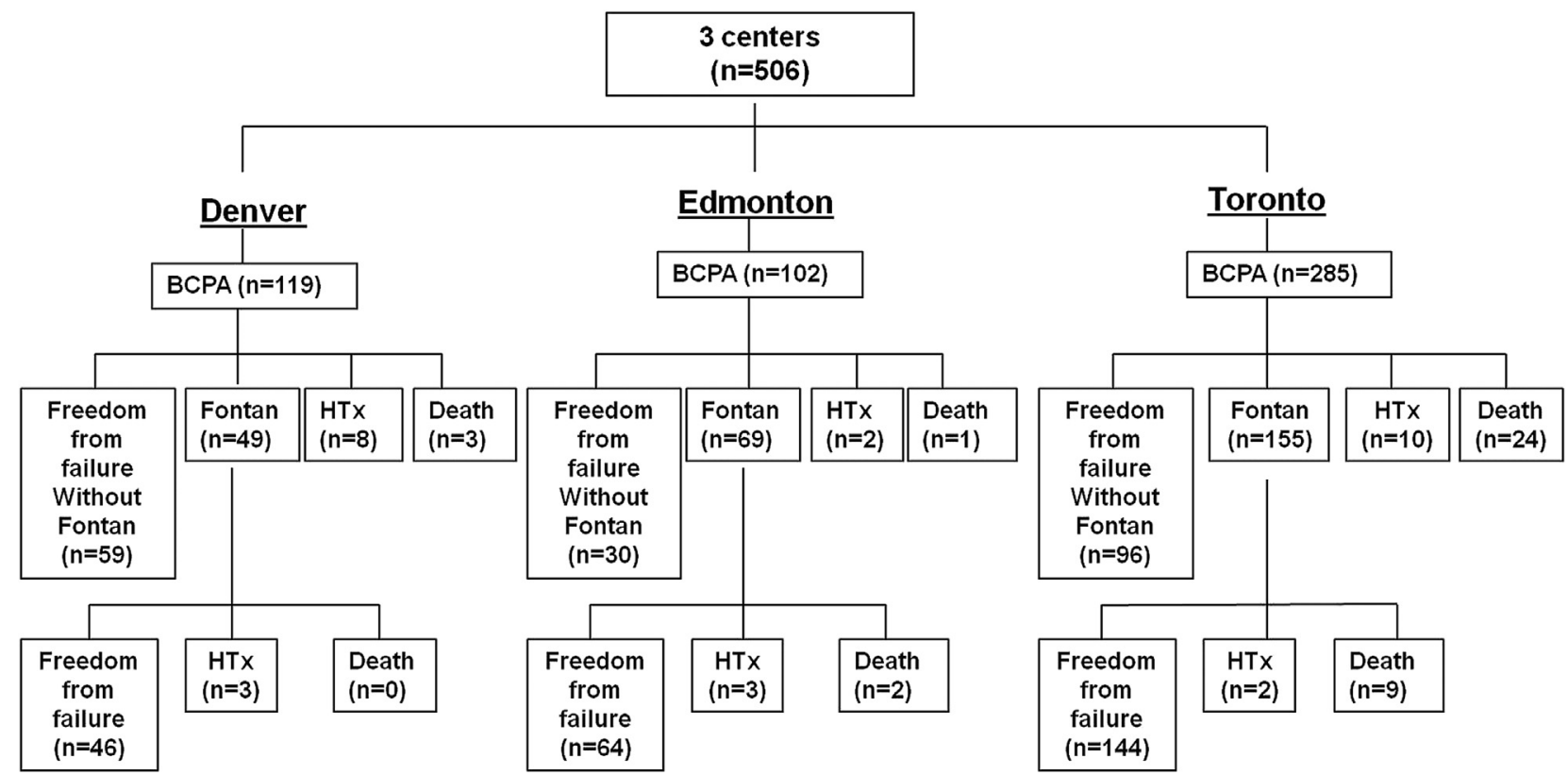

FIGURE 2. Postoperative outcomes in the 3 centers. BCPA, Bidirectional cavopulmonary anastomosis; $H T x$, heart transplantation.

In addition, PAP, PVR, and TPG decreased significantly from pre-BCPA to pre-Fontan assessments $(P<.0001$ for all) (Table 2). The decreases in the pulmonary hemodynamic variables between the 2 stages of operations were not correlated with altitude and other clinical variables $(P>.05$ for all). VEDP did not change significantly $(P=.31)$.

\section{DISCUSSION}

Direct comparison of data among the 3 centers of varying altitudes in Denver, Edmonton, and Toronto demonstrates that low to moderate altitude did not significantly correlate

TABLE 3. Comparison of the postoperative outcomes after BCPA and Fontan operations including the period of surgical hospitalizations and follow-up

\begin{tabular}{lccc}
\hline & Denver & Edmonton & Toronto \\
\hline BCPA & & & \\
$\quad$ No. of patients & 119 & 102 & 285 \\
$\quad$ Failure number & $11(9.2 \%)$ & $3(2.9 \%)$ & $34(11.9 \%)$ \\
$\quad$ Death & $3(2.5 \%)$ & $1(1.0 \%)$ & $24(8.4 \%)$ \\
$\quad$ Heart transplantation & $8(6.7 \%)$ & $2(2.0 \%)$ & $10(3.5 \%)$ \\
Fontan & & & \\
$\quad$ No. of patients & 49 & 69 & 155 \\
$\quad$ Failure no. & $3(6.1 \%)$ & $5(7.2 \%)$ & $11(7.0 \%)$ \\
$\quad$ Death & $0(0 \%)$ & $2(2.9 \%)$ & $9(5.7 \%)$ \\
$\quad$ Heart transplantation & $3(6.1 \%)$ & $3(4.3 \%)$ & $2(1.3 \%)$ \\
Survival numbers after BCPA & & & \\
$\quad \begin{array}{l}\text { y y } \\
5 \text { y }\end{array}$ & $115(96.6 \%)$ & $99(97.1 \%)$ & $260(91.2 \%)$ \\
10 y & $109(91.6 \%)$ & $95(93.1 \%)$ & $251(88.1 \%)$ \\
\hline
\end{tabular}

There was no statistical significance in the correlations between the centers and any of the values. $B C P A$, Bidirectional cavopulmonary anastomosis. with PAP, TPG, PVR, or VEDP at pre-BCPA or pre-Fontan catheterization, or with the rate of BCPA or Fontan failure. Risk factors for palliation failures included higher PVR, PAP, TPG, and the presence of a systemic right ventricle for all patients at varying altitudes.

Atmospheric pressure falls at a rate of $1 \%$ to $1.5 \%$ per 100 meters above sea level, which leads to reduction in the partial pressure of oxygen (and the oxygen level in the atmosphere is constantly $21 \%$ up to 110,000 meters). ${ }^{10}$ Thus, an atmospheric pressure of 750, 690, and $640 \mathrm{~mm} \mathrm{Hg}$ in Toronto, Edmonton, and Denver leads to the partial pressure of oxygen of 157, 145, and $134 \mathrm{~mm} \mathrm{Hg}$, respectively.

The first observation of hypoxic pulmonary vasoconstriction was made in 1894 when Bradford and Dean described increases in PAP in response to asphyxia. ${ }^{11}$ Half a century later, it was realized as an adaptive phenomenon by von $\mathrm{Eu}-$ ler and Liljestrand. ${ }^{12}$ In 1969, Marticorena and colleagues ${ }^{13}$ made the connection between sustained hypoxia and chronic hypoxic pulmonary hypertension at high altitude in Peru (4540 meters). The mechanism involves inhibition of oxygen-sensitive $\mathrm{K}^{+}$channels and activation of voltagegated $\mathrm{Ca}^{2+}$ channels of pulmonary artery smooth muscle cells, leading to $\mathrm{Ca}^{2+}$ influx and vasoconstriction, with subsequent proliferation of smooth muscle cells and a thickening of the artery wall. ${ }^{14}$ Structural changes of pulmonary arterioles by chronic hypoxia involve the small and muscular "resistance" pulmonary arteries, resulting in elevated PVR and right ventricular hypertrophy. ${ }^{15-18}$ Most of these studies have been conducted at high altitude above 3000 meters.

The conventional wisdom is that altitude, even low or moderate, should elevate PAP and PVR, thus adversely affect outcomes of cavopulmonary palliations in patients 

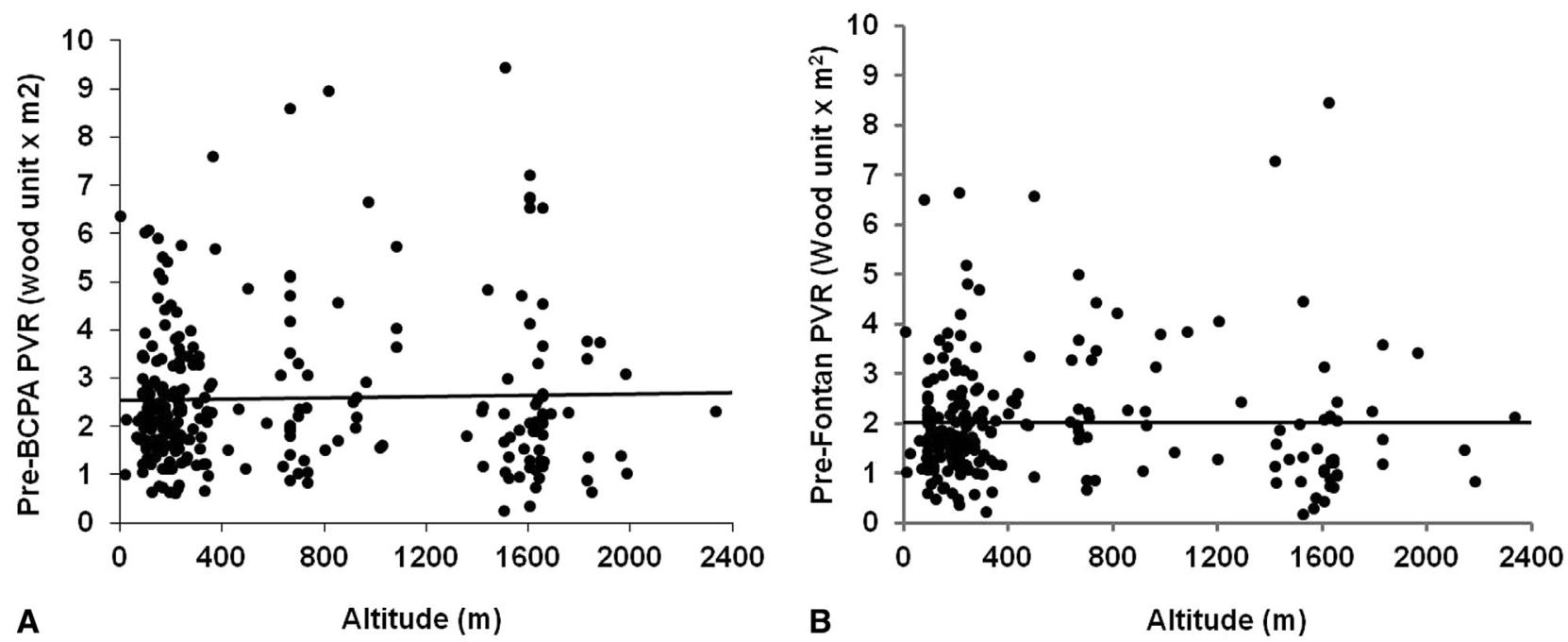

FIGURE 3. Correlations between altitude and PVR in all the patients from the 3 centers at (A) pre-BCPA and (B) pre-Fontan catheterization. $P V R$, Pulmonary vascular resistance; $B C P A$, bidirectional cavopulmonary anastomosis; HTx, heart transplantation.

with functional single ventricle. This was highlighted by a few clinical reports. McMahon, Hicks, and Dreyer ${ }^{19}$ reported a case of protein-losing enteropathy in a patient after relocation from sea level to a higher altitude (1230 meters). This resolved on moving back to a lower altitude. Darst and associates ${ }^{20}$ reported reduced exercise tolerance in patients residing in Denver compared with those in Toronto. Hosseinpour and associates ${ }^{6}$ reviewed published series from 24 centers with altitudes ranging up to 520 meters and found a correlation between altitude and early Fontan failure rate defined as death, takedown of Fontan, or transplantation. However, none of these studies assessed PAP or PVR.

In our study, pulmonary hemodynamic data were carefully collected from the pre-BCPA and pre-Fontan catheterization assessments and analyzed in relation with postoperative outcomes over a wide range of altitudes from sea level to 2572 meters. Within this range, altitude does not have a significant effect on PAP, TPG, PVR, VEDP, nor on their decreases from pre-BCPA to preFontan catheterization assessments, nor on palliation failures. Our findings support previous single-center studies

TABLE 4. Relationships between pulmonary hemodynamics as independent variables and palliation failure after BCPA and Fontan operation as dependent variables

\begin{tabular}{lccrcc}
\hline & \multicolumn{2}{c}{ BCPA failure } & & \multicolumn{2}{c}{ Fontan failure } \\
\cline { 2 - 3 } \cline { 5 - 6 } & Parameter estimate & $\boldsymbol{P}$ value & & Parameter estimate & $\boldsymbol{P}$ value \\
\hline PVR & 0.28 & .02 & & 0.27 & .4 \\
PAP & 0.05 & .2 & & 0.10 & .04 \\
TPG & 0.04 & .28 & & 0.08 & .06 \\
RV & 1.04 & .005 & & 0.05 & .6 \\
\hline
\end{tabular}

$B C P A$, Bidirectional cavopulmonary anastomosis; $P V R$, pulmonary vascular resistance; $P A P$, pulmonary arterial pressure; $T P G$, transpulmonary gradient; $R V$, right ventricle as the systemic ventricle. showing favorable outcomes at centers in Denver and Salt Lake City that are comparable with those at sea level. ${ }^{7,8}$ Further, in concordance with previous studies, the risk factors for palliation failures in patients at different altitudes identified in our study are higher PAP, TPG, PVR, and the presence of a systemic right ventricle. ${ }^{8,21}$

Several mechanisms may explain our findings. First, Denver is considered to be at low to moderate altitude (by altitude medicine standards), which leads to 20 to $30 \mathrm{~mm}$ $\mathrm{Hg}$ reduction in partial pressure of oxygen or $3 \%$ to $4 \%$ reduction of atmospheric oxygen level. Such reduction may not cause significant structural changes in the pulmonary vascular bed or changes in PAP or PVR, observed in higher-altitude residents or during acute acclimatization to moderate altitudes. Second, adaptive physiologic changes may occur in residents exposed to chronic hypoxia at elevated altitude, including increased systemic and pulmonary production of nitric oxide, leading to a lower PVR $^{3,22,23}$ This is different from acute acclimatization to altitude, which is likely to have happened in the reported post-Fontan patient in whom protein-losing enteropathy developed after relocation from sea level to a higher altitude. ${ }^{19}$ Palliative failures in patients with a functional single ventricle are related to the anatomic variations of congenital heart defects and consequent hemodynamic changes per se (such as higher PAP, TPG, PVR, and the presence of a systemic right ventricle ${ }^{8,21}$ ), but not altitude. As such, our study reemphasizes the importance of cardiac catheterization assessments of pulmonary hemodynamics before BCPA and Fontan operations.

\section{Limitations}

This study is subject to several limitations owing to its retrospective nature. First, inasmuch as only patients 
undergoing BCPA were enrolled in the study, some patients might have been precluded BCPA because of increased PAP or/and PVR. However, such patients are few in practice and these data were unavailable. Second, clinical practice varied among the centers. In Denver, for instance, patients with hypoplastic left heart syndrome tend to undergo heart transplantation more frequently, accounting for some of the difference in the distribution of cardiac diagnoses and surgical procedures before BCPA in the 3 centers. In addition, there were 2 patients in Denver who did not undergo the Fontan operation because of high PVR and were lost to follow-up. This may to some extent affect the postoperative outcomes, but it should not affect the main finding of our study, that is, the lack of relationship between altitude and PVR. Third, in Edmonton, clinical routine follow-up data collection was initiated much later than in the other 2 centers, accounting for the longer follow-up period. Therefore, the commonly used KaplanMeier methodology was considered not best to reflect the clinically "biased" situations among these 3 centers when used to examine the difference in freedom from failures. Fourth, some data, such as the occurrence of proteinlosing enteropathy and detailed assessments of myocardial function, were incomplete in some of the centers for comparison. Fifth, oxygen consumption was not directly measured, but calculated using predictive equations, which tend to induce errors in oxygen consumption values (especially the LaFarge equation for children younger than 3 years $\operatorname{old}^{24,25}$ ). To reduce these errors, we used the Lindulh equation to calculate oxygen consumption for all the patients from the 3 centers. ${ }^{24}$ In addition, there might be potential effect of altitude on oxygen consumption, but this remains unknown. ${ }^{3}$ Finally, patients with functional single ventricle undergoing staged palliations represent the most complex group of patients in pediatric cardiology and surgery, numerous factors such as congenital coexisting anomalies in anatomy and physiology, atrioventricular valve function, systemic ventricular function, and interstage interventions may have an impact on pulmonary vascularity and clinical outcomes. Our study focused on the effect of altitude on pulmonary hemodynamics in relation with postoperative outcomes. Further studies are warranted.

\section{CONCLUSIONS}

Low to moderate altitude does not have a significant impact on pulmonary hemodynamics and postoperative outcomes in patients with a functional single ventricle after cavopulmonary palliations. Patients from the 3 centers in Denver, Edmonton, and Toronto have similar outcomes after BCPA and the Fontan procedure. The risk factors for palliation failure in all patients identified in our study included higher PVR, PAP, TPG, and the presence of a systemic right ventricle, but not altitude. These findings should help to reorient clinical attention from the traditional focus on altitude to the anatomic variations of congenital heart defects and consequent hemodynamic changes. Our study reemphasizes the importance of cardiac catheterization assessments of pulmonary hemodynamics before BCPA and Fontan operations.

We thank Dr Bill Williams from Hospital for Sick Children, Toronto, Ontario, Canada for his critical review of the manuscript. We thank Sally Cai, the Statistician at the Data Center of Congenital Surgeons' Society, Toronto, Ontario, Canada, for her advice on statistics. We also thank Dr Arvin Abadilla, from Heart Center, Hospital for Sick Children, Toronto, Ontario, Canada, for his assistance in collecting additional data.

\section{References}

1. Mayer JE Jr, Bridges ND, Lock JE, Hanley FL, Jonas RA, Castaneda AR. Factors associated with marked reduction in mortality for Fontan operations in patients with single ventricle. J Thorac Cardiovasc Surg. 1992;103:444-51; discussion 451-2.

2. Hosein RB, Clarke AJ, McGuirk SP, Griselli M, Stumper O, De Giovanni JV, et al. Factors influencing early and late outcome following the Fontan procedure in the current era. The "two commandments?" Eur J Cardiothorac Surg. 2007; 31:344-52; discussion 353.

3. Erzurum SC, Ghosh S, Janocha AJ, Xu W, Bauer S, Bryan NS, et al. Higher blood flow and circulating NO products offset high-altitude hypoxia among Tibetans. Proc Natl Acad Sci U S A. 2007;104:17593-8.

4. Penaloza D, Arias-Stella J. The heart and pulmonary circulation at high altitudes: healthy highlanders and chronic mountain sickness. Circulation. 2007;115: 1132-46.

5. Cruz-Jibaja J, Banchero N, Sime F, Penaloza D, Gamboa R, Marticorena E. Correlation between pulmonary artery pressure and level of altitude: pressure and level of altitude. Chest. 1964;46:446-51.

6. Hosseinpour AR, Sudarshan C, Davies P, Nashef SA, Barron DJ, Brawn WJ. The impact of altitude on early outcome following the Fontan operation. $J$ Cardiothorac Surg. 2006;1:31.

7. Day RW, Orsmond GS, Sturtevant JE, Hawkins JA, Doty DB, McGough EC. Early and intermediate results of the Fontan procedure at moderately high altitude. Ann Thorac Surg. 1994;57:170-6.

8. Malhotra SP, Ivy DD, Mitchell MB, Campbell DN, Dines ML, Miyamoto S, et al. Performance of cavopulmonary palliation at elevated altitude: midterm outcomes and risk factors for failure. Circulation. 2008;118:S177-81.

9. Lindahl SG. Oxygen consumption and carbon dioxide elimination in infants and children during anaesthesia and surgery. Br J Anaesth. 1989;62:70-6.

10. Frisancho AR. Functional adaptation to high altitude hypoxia. Science. 1975; 187:313-9.

11. Calbet JA. Chronic hypoxia increases blood pressure and noradrenaline spillover in healthy humans. J Physiol. 2003;551:379-86.

12. Burtscher M, Philadelphy M, Likar R. Sudden cardiac death during mountain hiking and downhill skiing. N Engl J Med. 1993;329:1738-9.

13. Marticorena E, Ruiz L, Severino J, Galvez J, Peñaloza D. Systemic blood pressure in white men born at sea level: changes after long residence at high altitudes. Am J Cardiol. 1969;23:364-8.

14. Moudgil R, Michelakis ED, Archer SL. Hypoxic pulmonary vasoconstriction. J Appl Physiol. 2005;98:390-403.

15. Arias-Stella J, Saldana M. The terminal portion of the pulmonary arterial tree in people native to high altitudes. Circulation. 1963;28:915-25.

16. Saldana M, Arias-Stella J. Studies on the structure of the pulmonary trunk. I. Normal changes in the elastic configuration of the human pulmonary trunk at different ages. Circulation. 1963;27:1086-93.

17. Saldana M, Arias-Stella J. Studies on the structure of the pulmonary trunk. II. The evolution of the elastic configuration of the pulmonary trunk in people native to high altitudes. Circulation. 1963;27:1094-100.

18. Saldana M, Arias-Stella J. Studies on the structure of the pulmonary trunk. III. The thickness of the media of the pulmonary trunk and ascending aorta in high altitude natives. Circulation. 1963;27:1101-4.

19. McMahon CJ, Hicks JM, Dreyer WJ. High-altitude precipitation and exacerbation of protein-losing enteropathy after a Fontan operation. Cardiol Young. 2001;11:225-8. 
20. Darst JR, Vezmar M, McCrindle BW, Manlhiot C, Taylor A, Russell J, et al. Living at an altitude adversely affects exercise capacity in Fontan patients. Cardiol Young. 2010;20:593-601.

21. Scheurer MA, Hill EG, Vasuki N, Maurer S, Graham EM, Bandisode V, et al. Survival after bidirectional cavopulmonary anastomosis: analysis of preoperative risk factors. J Thorac Cardiovasc Surg. 2007;134:82-9, 89.e1-2.

22. Huez S, Faoro V, Guenard H, Martinot JB, Naeije R. Echocardiographic and tissue Doppler imaging of cardiac adaptation to high altitude in native highlanders versus acclimatized lowlanders. Am J Cardiol. 2009;103: 1605-9.
23. Ishizaki T, Koizumi T, Ruan Z, Wang Z, Chen Q, Sakai A. Nitric oxide inhibitor altitude-dependently elevates pulmonary arterial pressure in high-altitude adapted yaks. Respir Physiol Neurobiol. 2005;146:225-30.

24. Li J, Bush A, Schulze-Neick I, Penny DJ, Redington AN, Shekerdemian LS. Measured versus estimated oxygen consumption in ventilated patients with congenita heart disease: the validity of predictive equations. Crit Care Med. 2003;31:1235-40.

25. Rutledge J, Bush A, Shekerdemian L, Schulze-Neick I, Penny D, Cai S, et al. Validity of the LaFarge equation for estimation of oxygen consumption in ventilated children with congenital heart disease younger than 3 years-a revisit. Am Heart J. 2010;160:109-14. 